\title{
PHẪU THUẬT THÀNH CÔNG PHİNH ĐộNG MẠCH CHỦ BỤNG VÕ̃: KINH NGHIỆM TỪ MộT TRƯờNG HợP
}

\author{
Hán Văn Hòa ${ }^{*}$, Trương Văn Hải ${ }^{*}$, Dương Xuân Phuơng ${ }^{*}$
}

\section{TÓM TÁ́T}

Phình động mạch chủ bụng vỡ là cấp cứu đe dọa tính mạng. Nếu không chấn đoán và can thiệp kịp thời, tỷ lệ tử vong lên đến 90 $100 \%[1]$,[2]. Triệu chứng trầm trọng và bệnh cảnh phức tạp dẫn đến chẩn đoán sai. Phẫu thuật là lựa chọn ưu tiên khi sốc, huyết động không ổn định, giải phẫu học bất lợi. Tuy nhiên, tỷ lệ tai biến, biến chứng và tử vong còn cao. Phân tích ca bệnh nhằm mang lại cách nhìn sâu hơn về chẩn đoán và điều trị phình động mạch chủ bụng vỡ cho đồng nghiệp.

Từ khóa: phình động mạch chủ bụng vỡ, phình động mạch chủ.

SUMMARY: Ruptured aortic aneurysm is a life-threatening emergency. If it wasnot diagnosed and intervened well, the mortality ratemight be $90-100 \%[\underline{1}]$,[2] . Severe symptoms and complicated illnesses lead tomisdiagnosis. Surgery is the priority choice when shock, hemodynamic instability, and anatomical disadvantages are observed.However, the rate of disastions, complications and deaths is still high. Analysis of a specific case aims toprovide colleagues with a better understandingof the diagnosis and treatment abdominal aortic aneurysm rupture.

Key words: abdominal aortic aneurysm rupture, abdominal aortic aneurysm.

\section{I. ĐẶT VẤN ĐỀ}

Phình động mạch chủ bụng vỡ là một cấp cứu, đe dọa trực tiếp tính mạng người bệnh và là thách thức của phẫu thuật mạch máu.Nếu không được chẩn đoán và điều trị kịp thời, tỷ lệ tử vong lên đến $90-100 \%[1]$,[2] .TheoJorn $\mathrm{P}$. và cs[]ㅡ phình có đường kính $>8 \mathrm{~cm}$, tỷ lệ vỡ tăng từ $30-$ $50 \% /$ năm.Nếu như phình động mạch chủ bụng hầu hết không triệu chứng, phát hiện tình cờthìtriệu chứng vỡ phình rầm rộ và đa dạng với bệnh cảnh khác nhau. Chẩn đoán ban đầu các bệnh tiêu chảy, viêm phúc mạc, viêm tụy cấp, thủng ổ loét dạ dày, sốc nhiễm trùng nhiễm độc. Chính vậy, nhiều trường hợp phình mạch chủ bụng vỡ không phát hiện, xử trí kịp thời, thậm chí tử vong chưa xác định nguyên nhân.

Với phình động mạch chủ bụng vỡ, chỉ định can thiệp đặt stent graf phụ thuộc nhiều yếu tố:huyết động ổn định, hình dạng khối phình, trình độnhân lực, trang thiết bị hiện đại[4], [5]. Bên cạnh đó, phẫu thuật mở lạilà một thách thức lớn nhất là khi sốc nặng, huyết động dao động, biến đổi giải phẫu rất nhiều, bệnh kèm theo phức tạp, cao tuổi, rối loạn động máu. Do đó dù phẫu thuật nhưng tỷ lệ tai biến, biến chứng và tử vong rất cao.

Bệnh viện đa khoa tỉnh Phú Thọ đã được trang bị hệ thống can thiệp mạch đồng bộ và hiện đại, cùng nguồn nhân lực can thiệp mạch được đào tạo chuẩn. Tuy nhiên, can thiệp nội mạch cho phình động mạch chủ bụng nói chung và phình vỡ chưa được thực hiện.

Với những lý do trên, chúng tôi báo báo trường hợp phình động mạch chủ bụng vỡ thứ phát sốc rất nặng,ần đầu tiên được phẫu thuật thành công

*Đon vị phẫu thuật Tim mạch - Lồng ngục Bệnh viện tỉnh Phú Thọ Người chịu trách nhiệm khoa học: BS Dương Xuân Phương Ngày nhận bài: 01/05/2019 - Ngày Cho Phép Đăng: 15/05/2019 Phản Biện Khoa họ: PGS.TS. Đặng Ngoc Hùng GS.TS. Lê Ngoc Thành 
tại Bệnh viện Phú Thọ không tai biến và biến chứng gì,nhằm đưa ra cách nhìn sâu hơn về chẩn đoán, xử trí phìnhđộng mạch chủ vỡ cho đồng nghiệp.

\section{BÁO CÁO CA LÂM SÀNG}

Nữ giới, 66 tuổi, ởTrung Sơn-Yên LậpPhú Thọ. Mã bệnh án MR 1441087.Tiền sử tăng huyết áp không điều trị thường xuyên.Người bệnh vào lúc 20h ngày 23/1/2019, phẫu thuật lúc 4h ngày 24.1 .19 (sau 8 tiếng) với chẩn đoán sốc nặng do phình động mạch chủ bụng vỡ. Trước đó 2 ngày, người bệnh đột ngột đau bụng và lưng, tiêu chảy và ngất. Chẩn đoán ban đầu tại Trung tâm y tế huyện là tiêu chảy cấp mất nước. Siêu âm thấy phình động mạch chủ bụng vỡ, chuyển bệnh viện tỉnh.

Lúc vào, người bệnh sốc, thiếu máu rõ, huyết áp 90/60 mmHg phụ thuộc Noradrenalin. Bệnh nhân lơ mơ, kích thích cơn, tự thở, đau bụng dữ dội, bụng trướng, phản ứng thành bụng. CT bụng có thuốc và siêu âm: phình động mạch chủ dưới thận, vỡ, tụmáu sau phúc mạc, dịch máu trong ổ bụng, đường kính khối phình 9,06 cm, không huyết khối bám thành, có hình ảnh liềm thoát thuốc mặt trước - bên phải.

Diễn biến, khi chưa kịp khởi mê, huyết áp chỉ 70/50 mmHg, nhanh chóng vừa đặt ống NKQ, vừa mở bụng, dùng 2 loại thuốc vận mạch, dịch, máu truyền thành dòng, đầu dốc $45^{\circ}$. Ổ bụng có dịch máu và máu tụ rất lớn sau phúc mạc. Khi bắt đầu mở phúc mạc thành sau thì khối phình bật máu cục (vị trí thoát mạch trên phim), phun máu dữ dội, huyết áp chỉ ở mức 40- 50 mmHg. Chúng tôi vừa đặt gạc, chẹn ngay vị trí vỡ, vừa ấn tay phía trên vị trí phình, vừa bộc lộ cổ trên khối phình. Đồng thời, hạ đầu thấp hơn nữa. Sau thời gian ngắn (dưới 10 phút), chúng tôi đã khống chế được cổ trên khối phình và tiếp đến động mạch chậu gốc 2 bên. Sau mở khối phình, thành mạch ít xơ vữa, không huyết khối. Thực hiện thay đoạn phình vỡ bằng đoạn mạch nhân tạo thẳng. Dòng trào ngược động mạch mạc treo tràng dưới tốt, quyết định thắt lại. Duy trì kẹp 2 bên rồi từng bên động mạch chậu trong 15 phút, mới có thể thả hoàn toàn kẹp mạch, huyết áp đưa lên duy trì 130 mmHg với 3 thuốc vận mạch liên tục.Sau 4 tiếng cuộc mổ kết thúc thành công. Thở máy hỗ trợ 10 tiếng, rút ống NKQ và giảm dần và cắt vận mạch, duy trì Nicardipin hạ áp.

Sau mổ xuất hiện rối loạn đông máu, tiểu cầu $87.10^{9} / 1$, PT 25\%; APTT 66,9s,không sử dụng Heparin sau mổ, nguy cơ chảy máu rất cao. Trong và sau mổ, chúng tôi đã truyền 3,5 lít $\mathrm{KHC}, 1,5$ lít huyết tương, $450 \mathrm{ml}$ khối tiểu cầu. Ngày thứ 3 ổn định, PT 72\%, APTT 35,4s, tiểu cầu148.10\% /1,không suy gan, thận (AST 42,4 $\mathrm{mmol} / \mathrm{L}$, ALT 47,6 mmol/L, Ure 4,34 mmol/L, Creatinin: $57 \mathrm{mmol} / \mathrm{L})$, tiểu tốt, huyết động ổn. Ngày thứ 4 ăn uống được, ngày thứ 6 đi lại tại giường, ngày thứ 8 ra viện mà không hề tai biến, biến chứng sảy ra. Khám lại 1 và 2 tháng sau mổ, bệnh nhân hoàn toàn bình phục, mạch tốt.

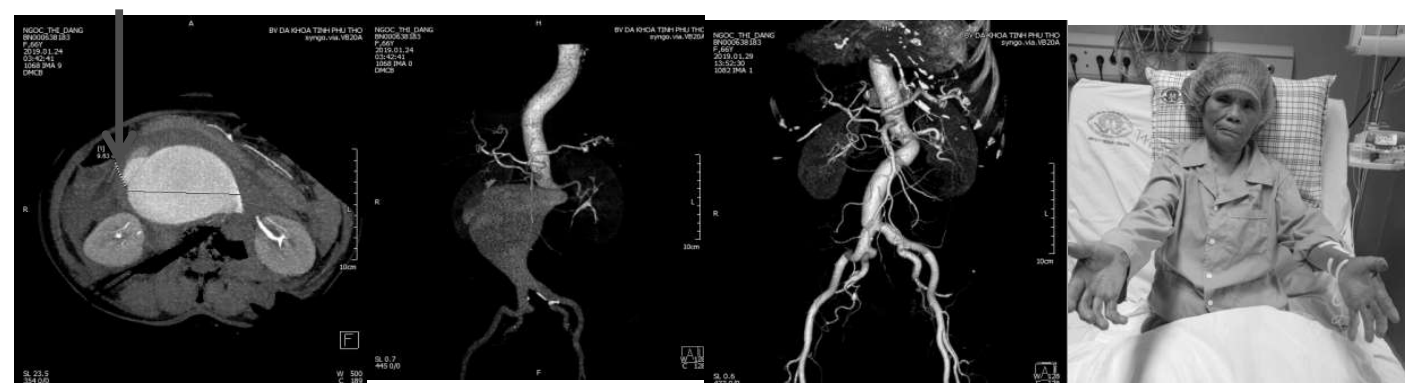

Trước mổ (liềm thoát thuốc)

Sau mổ ngày thứ 6 ổn định 


\section{BÀN LUẬN}

\subsection{Yếu tố nguy co'}

Động mạch chủ bụng giãn khu trú với đường kính $>3 \mathrm{~cm}$ gọi là phình. Nguy cơ vỡ khối phình tăng theo kích thước và phụ thuộc nhiều yếu tố như giới nữ, cao tuổi, tăng huyết áp, hút thuốc, sự bất ổn định huyết khối trong khối phình, tốc độ tăng kích thước, mức độ gấp góc. Cơ chế vỡ phình theo định luật La place và các yếu tố khác: huyết khối, tế bào viêm, giảm tính đàn hồi do giảm elastin, tăng collegen thành mạch[1]].Tốc độ tăng trưởng phình ở nữ tăng nhanh hơn, tỷ lệ vỡ gấp 4 lần, tử vong do vỡ cao hơn 3 lần nam, đường kính khi vỡ ở nữ nhỏ hơn ở nam 5 - 10 mm[2] $]$,

Các dữ liệu của người bệnh được báo cáothuộc nhóm nguy cơ cao: nữ giới, cao tuổi (66 tuổi), tăng huyết áp không điều trị, khối phình gập góc lớn $\left(120^{0}\right)$ làm tăng áp lực dòng máu lên thành mạch nhất là không huyết khối bám thành. Dấu hiệu thoát thuốc cho thấy khối đang vỡ và nguy cơ vỡ thì 2 rất cao.

\subsection{Chẩn đoán}

Chẩn đoán phình động mạch chủ bụng chưa vỡ khá đơn giản, nhiều trường hợp phát hiện tình cờ. Tuy nhiên, phình vỡ, các triệu chứng xuất hiện đột ngột, diễn biến nhanh với biểu hiện đồng thời ở nhiều cơ quan khác nhau như: tri giác, tiêu hóa, tuần hoàn, tiết niệu, chi dưới... khiến cho chẩn đoán ban đầu khó khăn, đặc biệt khi huyết động người bệnh không cho phép thực hiện cận lâm sàng.
Dấu hiệu lâm sàng điển hình phình mạch chủ bụng vỡ là ở người trên 50 tuổi: đột ngột đau bụng và/hoặc đau lưng dữ dội, hạ huyết áp, khối vùng bụng đập theo nhịp[6]

Các trường hợp không điển hình có thể: tê liệt chi dưới thoáng qua, rối loạn chức năng tinh hoàn, huyết khối tĩnh mach chậu, u ở phổi kèm theo đau và tím tái chi dưới, hạ áp, Đặc biệt ngất rất hay gặp, thậm chí sốc, hồi sức tim phổi[7]],[]]... dẫn đến chẩn đoán sai 16 - 62\%. Ngoài ra, tới $25 \%$ các trường hợp không được chẩn đoán ban đầu đầy đủ, các chẩn đoán thay thế là viêm ruột thừa, đau bụng không đặc hiệu, tắc ruột, xoán tinh hoàn, viêm tụy cấp, viêm phổi, chảy máu đường tiêu hóa trên, vỡ ống dẫn tinh (12 bệnh khác nhau) và ở Hoa Kỳ, mức độ chẩn đoán sai $30 \%$ [8] $]$ Sự chẩn đoán sai có thể do khối máu tụ sau phúc mạc, ví dụ đau tinh hoàn do chèn ép thần kinh sinh dục, tiêu chảy do kích thích đại tràng, vô niệu do chèn ép niệu quản... Các triệu chứng khác gây khó như rối loạn huyết động, giảm thông khí, nôn mửa... Tuy nhiên, chưa có dữ liệu cho thấy tỷ lệ tử vong tăng lên do chẩn đoán cấp cứu ban đầu sai[]].

Bệnh nhân của chúng tôi có dấu hiệu gợi ý rõ: đau bụng đột ngột lan sau lưng, ngất và huyết áp tụt. Tuy nhiên, dấu hiệu khối phình đập theo nhịp không được đề cập đến. Có thể, bụng trướng, phản ứng thành bụng phần nào gây khó khăn cho phát hiện khối phình ở bụng, nhất là khi trước đó chưa biết phình động mạch chủ bụng. 
Mặt khác, bệnh nhân buồn nôn, tiêu chảy 4 lần/ngày. Do đó, chẩn đoán ban đầu là tiêu chảy cấp, mất nước.

Cũng phải lưu ý rằng, phình động mạch chủ bụng vỡ thường ở người tăng huyết áp, do đó, dấu hiệu tụt huyết áp dựa trên huyết áp nền của người bệnh.

Siêu âm bụng và chụp cắt lớp có thuốc rất quan trọng cho chẩn đoán phình động mạch chủ bụng vỡ. Kết quả siêu âm bụng tuyến cơ sở và của chúng tôi tương tự nhau, với khối phình kích thước lớn hơn $9 \mathrm{~cm}$, trong khối có ít huyết khối bám thành, nhiều tổ chức tăng âm sau phúc mạc, dịch dạng máu trong ổ bụng. Nhờ siêu âm mà có thể chẩn đoán sớm xong khó đánh giá hình dạng khối phình, vị trí chia và tình trạng động mạch thận.

CT bụng có thuốc là tiêu chuẩn vàng chẩn đoán và định hướng phẫu thuật. $\underline{\text { Rakita } \mathrm{D}}$ và cs [9] cho biết, hầu hết biểu hiện khối máu tụ sau phúc mạc lan rộng vùng chậu, khoang gan thận, chèn ép cơ thắt lưng, kèm theo phình động mạch chủ bụng.Những phát hiện này có thể thấy được trên hình không cản quang. Sự gián đoạn thành động mạch chủ hay khoảng cách vôi hóa chu vi thành động mạch chỉ ra vị trí vỡ, thậm chí hình ảnh xuất huyết nội thành là dấu hiệu sắp vỡ.

Bên cạnh chẩn đoán xác định phình động mạch chủ bụng dưới thận vỡ. Đặc điểm nổi bật trong hình ảnh $\mathrm{CT}$ của ca bệnh là sự thoát thuốc (đặc trưng vỡ tiến triển). Liềm ngoại vi được xác định rõ bên cạnh khối phình là một dấu hiệu CT của vỡ cấp tính, nó đại diện cho sự tách máu vào trong huyết khối ngoại biên hay thành khối phình và là biểu hiện sớm và cụ thể nhất quá trình vỡ.Khối phình lớn, không huyết khối bám thành, cách động mạch thận $(2 \mathrm{~cm})$, nhu mô thận ngấm thuốc tốt. Nhờ đó, tiên lượng phẫu thuật khả thi.

\subsection{Phẫu thuật}

Phình động mạch chủ bụng vỡ có thể can thiệp nội mạch đặt stent hoặc phẫu thuật mở. Can thiệp nội mạch huận lợi khi huyết động ổn và hình ảnh khối phình cho phép. Huyết động không ổn định là sốc trước phẫu thuật (huyết áp < 90mmHg) hoặc truyền máu $>4$ đơn vị, hôn mê, đột quỵ, thở máy,hồi sức tim phổi [1] Giải phẫu không phù hợp can thiệp là: đường kính cổ trên $>32 \mathrm{~mm}$, chiều dài cổ trên $<10 \mathrm{~mm}$, góc $\alpha>110^{0}[\underline{10}]$.

Lựa chọn can thiệp duy nhất của chúng tôi là phẫu thuật khẩn cấp. Vì bệnh nhân sốc với huyết áp 90/60 mmHg phụ thuộc Noradrenalin và tụt xuống 70/50 mmHg trước khởi mê. Đồng thời, khối phình có góc $\alpha 120^{\circ}$,cũng là chống chỉ định đặt stent graf mặc dù khả năng phục hồi của can thiệp nội mạch nhanh hơn và thuận lợi hơn phẫu thuật.

Tuy nhiên, gây mê và phẫu thuật cũng là thách thức. Để giảm nguy cơ và mức độ nặng của sốc. Chúng tôiđã truyền máu, dịch cao phân tử trước mổ, tránh hạ thân nhiệt bằng thảm điều nhiệt. Đồng thời, khởi mê thực hiện khi mọi thứ đã sã̃n sàng cho rạch da, bởi thuốc giãn cơ thành bụng, huyết áp tụt nhanh, giảm áp lực đột ngột gây vỡ khối máu tụ vào trong phúc mạc, tăng độ nặng 
sốc, thiếu máu tim, não khó hồi phục. Do huyết áp tiếp tục giảm thấp, dấu hiệu vỡ tiến triển buộc chúng tôi vừa mở bụng, vừa đặt ống nội khí quản. Kịch tính diễn ra khi khối phình vỡ thì 2, lượng máu mất nhiều và đột ngột, nguy cơ mất não, ngừng tim rất cao. Vì vậy, chúng tôi vừa đè ép phía trên khối phình vừa bịt tay tại vị trí vỡ, dốc đầu người bệnh $45^{\circ}$ (ưu tiên máu cho não, tim), truyền máu thành dòng, nhanh chóng bộc lộ cổ trên. Tiếp đó là thả clamp mạch chậu khi huyết áp duy trì >130 mmHg tránh sốc không phồi phục.

Một số quan điểm chủ trương kẹp chéo phía trên động mạch thận do che khuất tầm nhìn phẫu thuật của khối máu tụ. Tuy nhiên tỷ lệ suy thận, nhồi máu thận rất cao.

\subsection{Tai biến và biến chứng}

Sốc mất máu ở người bệnhcao tuổi, nhiều bệnh phối hợp, tai biến, biến chứngthiếu máu não, tim, thận, rối loạn đông máu, chảy máu, viêm phổi là nguyên nhân tăng tỷ lệ tử vong và di chứng sau mổ.

Bệnh nhân của chúng tôi, chỉ thở máy hỗ trợ rất ngắn (10 tiếng), tiểu tốt ngay sau mổ, không tổn thương tạng xung quanh trong mổ. Rối loạn đông máu được dự đoán và điều trị tích cực. Các chỉ số chức năng gan, thận và đông máu ngày thứ 3 hoàn toàn ổn định. Phần do sức chịu đựng của bệnh nhân tốt, xong quan trọng hơn là phẫu thuật khẩn cấp, ưu tiên tưới máu cho não, tim trong mổ, khối phình xa động mạch thận, thuận lợi cho khống chế mạch. Nghiên cứu của
Gawenda $M$ và cs [11] kết luận: suy thận sau mổ26 - 42\%, trong đó $11-40 \%$ cần lọc máu, trong đó $76 \%$ đến $89 \%$ tử vong. Prateek K. và cs [12] nghiên cứu 466 trường hợp huyết động không ổn định được phẫu thuật. Nhồi máu, ngưng tim trong 30 ngày sau mổ $29 \%, 18,7 \%$ lọc máu. Thở máy 48 giờ chiếm $45 \%$, phẫu thuật lại $21 \%$.

\section{KẾT LUẬN}

Phình động mạch chủ bụng vỡ khởi đầu thường đột ngột với bệnh cảnh đa dạng dễ chuẩn đoán sai và nguy cơ tử vong cao. Chẩn đoán sớm bằng $\mathrm{CT}$ có thuốc. Tuy tỷ lệ tai biến, biến chứng và tử vong cao xong phẫu thuật khẩn cấp vẫn có thể thành công nếu đảm bảo máu cho não, tim trong mổ.

\section{TÀI LIỆ THAM KHẢO:}

1. Jeanmonod, D. and R. Jeanmonod, Aneurysm, Abdominal Aortic Rupture (AAA), in StatPearls. 2019: Treasure Island (FL).

2. Soares Ferreira R, G.O.N., OliveiraPinto J, van Rijn MJ, Ten Raa S, Verhagen HJ3, Bastos Gonçalves F, Review on management and outcomes of ruptured abdominal aortic aneurysm in women. J Vasc Surg., 2019. 69(3): p. 792-799.

3. Jorn P. Meekel, T.G.v.S., Michiel L.P. van Zeeland, Kak K. Yeung, Arjan W.J. Hoksbergen Repeat Rupture of a Giant Abdominal Aortic Aneurysm after EVAR. EJVES Short Reports., 2019. 43: p. 15 - 17.

4. Tiehao Wang, M., Jichun Zhao, MD, $\mathrm{PhD}^{*}$, Ding Yuan, MD*, Yukui Ma, MD, Bin Huang, MD, and M. Yi Yang, Guojun Zeng, MD, Comparative effectiveness of open surgery versus endovascular repair for hemodynamically stable and unstable ruptured abdominal aortic aneurysm. Wang et al. Medicine, 2018. 
5. Ko, D., et al., Early experiences of Diagnosis of ruptured abdominal aortic endovascular aneurysm repair for ruptured abdominal aortic aneurysms. Ann Surg Treat Res, 2019. 96(3): p. 138-145.

aneurysm: a multicentre cohort study. Br J Surg., 2016. 103(12): p. 1634-1639.

6. David Metcalfe, K.S., Sri G. findings in rupture and impending rupture of Thrumurthy, Matthew M. Thompson, and abdominal aortic aneurysms. Radiographics, P.J.H.a.A.P. Karthikesalingam, Diagnosis of 2007.27(2): p. 497-507.

ruptured abdominal aortic aneurysm: a multicentre cohort study. European Journal of Emergency Medicine, 2015.

7. Kei Aizawa, M., Shinichi Ohki, MD, and Yoshio Misawa, MD, Open Surgical Decompression Is Useful for the Prevention and Treatment of Abdominal Compartment Syndrome after the Repair of Ruptured Abdominal Aortic and Iliac Artery Aneurysm. Annals of Vascular Diseases, 2018. Vol. 11, No. 2: p. 196-201.

8. Metcalfe D, S.K., Thrumurthy SG, Thompson MM, Holt PJ, Karthikesalingam AP,

10. Wang, T., et al., Comparative effectiveness of open surgery versus endovascular repair for hemodynamically stable and unstable ruptured abdominal aortic aneurysm. Medicine (Baltimore), 2018. 97(27): p. e11313.

11. Brunkwal, M.G.a.J., Ruptured Abdominal Aortic Aneurysm. Deutsches Ärzteblatt International, 2012. 109(43): p. 32.

12. Gupta, P.K., et al., A comparison of open surgery versus endovascular repair of unstable ruptured abdominal aortic aneurysms. J Vasc Surg, 2014. 60(6): p. 1439-45. 